\title{
Glycerol mycolates from synthetic mycolic acids
}

Ali, Omar Thanoon; Sahb, Mohaned M.; Al-Dulayymi, Juma'a; Baird, Mark

\section{Carbohydrate Research}

DOI:

10.1016/j.carres.2017.04.023

Published: 07/08/2017

Version created as part of publication process; publisher's layout; not normally made publicly available

Cyswllt i'r cyhoeddiad / Link to publication

Dyfyniad o'r fersiwn a gyhoeddwyd / Citation for published version (APA):

Ali, O. T., Sahb, M. M., Al-Dulayymi, J., \& Baird, M. (2017). Glycerol mycolates from synthetic mycolic acids. Carbohydrate Research, 448, 67-73. https://doi.org/10.1016/j.carres.2017.04.023

\footnotetext{
Hawliau Cyffredinol / General rights

Copyright and moral rights for the publications made accessible in the public portal are retained by the authors and/or other copyright owners and it is a condition of accessing publications that users recognise and abide by the legal requirements associated with these rights.

- Users may download and print one copy of any publication from the public portal for the purpose of private study or research.

- You may not further distribute the material or use it for any profit-making activity or commercial gain

- You may freely distribute the URL identifying the publication in the public portal ?
}

Take down policy

If you believe that this document breaches copyright please contact us providing details, and we will remove access to the work immediately and investigate your claim. 


\section{Glycerol mycolates from synthetic mycolic acids}

Omar T. Ali, Mohaned M. Sahb, Juma'a R. Al Dulayymi and Mark S. Baird, School of Chemistry, Bangor University, Bangor, Gwynedd, Wales, UK LL57 2UW Abstract: $R$ - and S-Glycerol mycolates derived from single synthetic $\alpha$-, keto- and methoxy-mycolic acids, such as compound A are described.

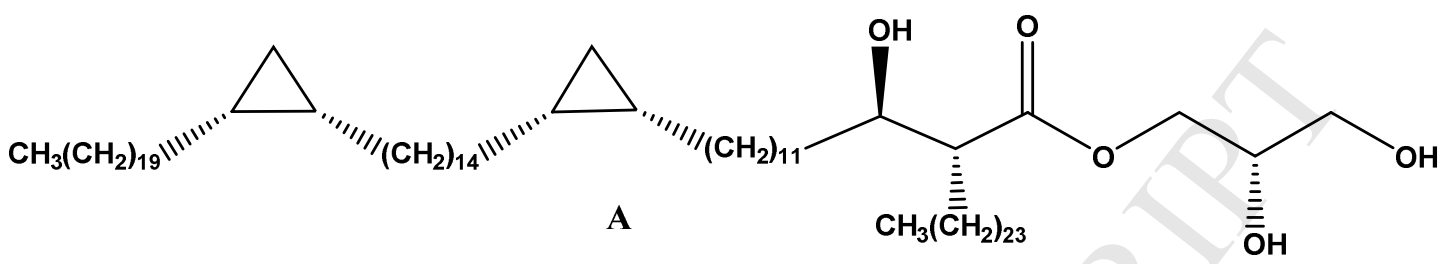




\title{
Glycerol mycolates from synthetic mycolic acids
}

\author{
Omar T. Ali, Mohaned M. Sahb, Juma'a R. Al Dulayymi and Mark S. Baird,*
}

School of Chemistry, Bangor University, Bangor, Gwynedd, Wales, UK LL57 2UW

Abstract: $R$ - and S-Glycerol mycolates derived from single synthetic $\alpha$-, keto- and methoxymycolic acids are described.

Keywords: GroMM, glycerol mycolate, $\alpha$-mycolic acid, keto-mycolic acid, methoxymycolic acid

*Corresponding author: e-mail chs028@ bangor.ac.uk

\section{Introduction}

Complex mixtures of mycolic acids are characteristic components of mycobacterial cells, either bound to the wall as arabinose esters or not bound to the wall, as free acids or esterified to sugars such as glucose (GMM), or trehalose (dimycolate, TDM; monomycolate, TMM) [1]. As early as 1956, it was shown that Mycobacterium tuberculosis contains mycoloylglycerols (ca. 90 carbons) [2 - 5]. Glycerol monomycolate (GroMM, also known as $\mathrm{MMG}$ ) is also present in the wax $\mathrm{C}$ fraction of BCG [6]. Shorter chain glycerol esters were isolated from Nocardia rhodochrous, which contains nocardomycoloylglycerols (40 - 44 carbons) [7], from Corynebacterium pseudotuberculosis (30 - 36 carbons) [8], from Nocardia asteroides (50 - 56 carbons) [9], and from Rhodococcus lentifragmentus (32 - 50 carbons) [10].

The glycerol is esterified at one of the primary alcohol groups [11]. The antigen isolated from Mycobacterium bovis BCG was shown to exist as two stereoisomers at the glycerol by comparison of the NMR spectrum with those of $R$ - and $S$-glycerol isomers of GroMM prepared from mycolic acid mixtures isolated from M.tuberculosis H37Rv cells [12]. Both semi-synthetic GroMMs stimulate CD-1 restricted $\mathrm{T}$ cell clones, the $R$-isomer being more slightly more stimulatory than GroMM from Mycobacterium bovis $B C G$, the $S$-isomer slightly less stimulatory. In this system, $R$ and $S$-isomers of GroMM prepared from a 32 carbon corynomycolate almost completely removed the stimulatory effect, in line with earlier results [13]. The secondary alcohol group of the glycerol was also necessary for activity. GroMM was presented by $M$. tuberculosis infected dendritic cells, demonstrating that the antigen is available for presentation during natural infection. Ex vivo experiments showed that GroMM stimulated $\mathrm{T}$ cells from vaccinated or latently infected healthy donors but not those from patients with active tuberculosis, suggesting that GroMM-specific $\mathrm{T}$ cells are primed during infection and their detection correlates with lack of clinically active disease [12]. Hattori et al. immunized guinea pigs with bacillus Calmette-Guérin (BCG) expressing high levels of GroMM and then monitored skin reactions at the site of inoculation with GroMM-containing liposome. The host responses to GroMM produced by dormant mycobacteria contribute to their long-term survival in the host [14], again identifying GroMM 
as potentially associated with latent infection. GroMM is a ligand for the human, but not mouse macrophage inducible c-type lectin, Mincle [15], the signalling process being dependent on structure $[16,17]$.

A 32 carbon monomycolyl GroMM analogue demonstrated enhanced immunostimulatory activity in a dioctadecyl ammonium bromide/Ag85B-ESAT-6 formulation. Elevated levels of IFN-gamma and IL-6 were produced in spleen cells from mice immunised with a 32 carbon GroMM analogue comparable activity to the potent Th1 adjuvant, trehalose 6,6'-dibehenate [18 - 22]. Interest in the properties and applications of GroMMs therefore remains high [23 26].

Derivatives of GroMMs in which the two other glycerol alcohol groups are acylated have also been reported [27].

Layre et al. prepared GroMM using potassium salts of mixtures of mycolates isolated from M. tuberculosis H37Rv [12], using (S)- and (R)-isopropylidene-glycerol $p$-toluenesulfonates 1 and 2 (Scheme 1).

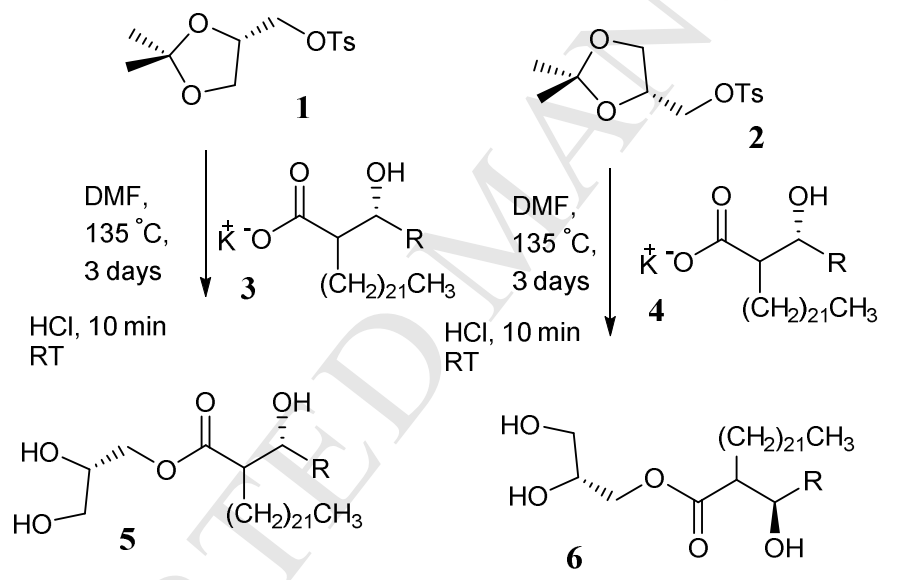

Scheme 1: The synthesis of GroMM with natural mycolic acid [13]

Nordly et al. synthesised GroMMs from unfunctionalised $\mathrm{C}_{32} \beta$-hydroxy acids producing a mixture of four stereoisomers, and carried out extensive studies of their bioactivity [21].

In order to determine whether the detailed structure of the individual mycolic acid in the natural mixtures leads to changes in their biological properties, or whether the activity is dominated by the glycerol fragment, we now report the synthesis of GroMMs based on coupling of a set of individual complete synthetic mycolic acids, taken from various Mtb classes, with both glycerol stereoisomers.

\section{Results and discussion}

The synthetic mycolic esters of $R$-glycerol 10 were prepared by two methods. In the first, the TBDMS protected MA was coupled with acetonide 8 promoted by DCC and DMAP. In the 
second, the unprotected acid was coupled with tosylate $\mathbf{2}$ in the presence of cesium hydrogen carbonate. (Scheme 2)

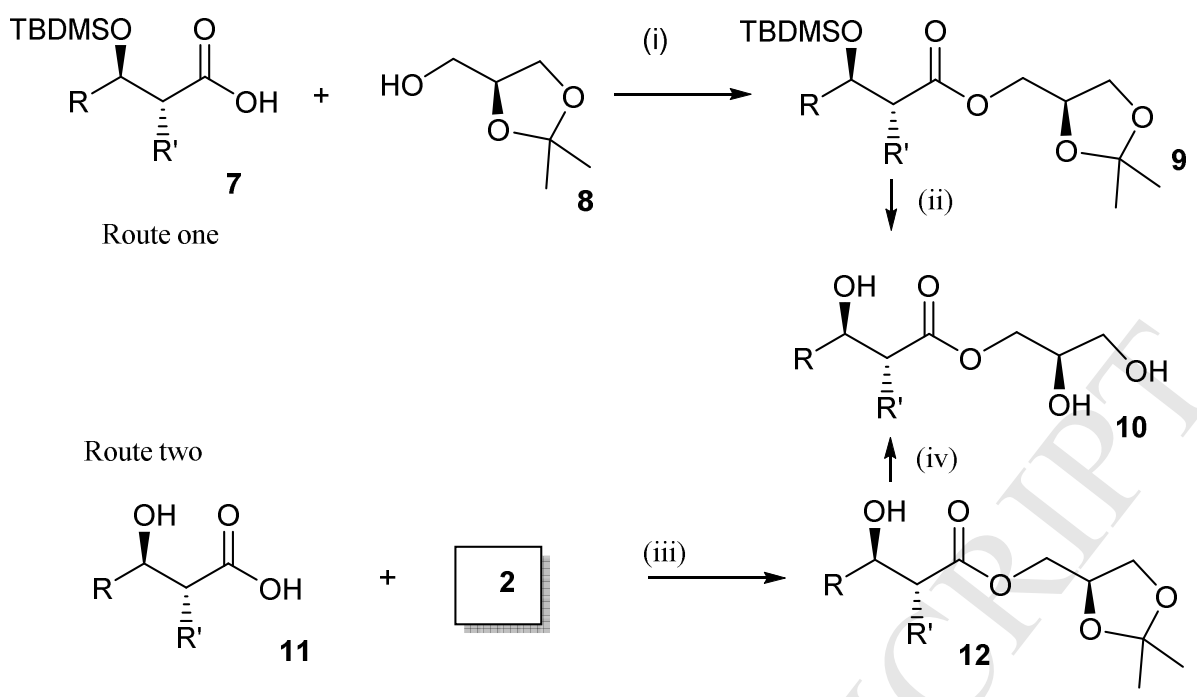

Scheme 2: (i) DMAP, DCC; (ii) TFA, $\mathrm{CH}_{2} \mathrm{Cl}_{2}$; (iii) $\mathrm{CsHCO}_{3}$; (iv) $\mathrm{HCl}, \mathrm{THF}, \mathrm{H}_{2} \mathrm{O}$

Table 1: Synthetic mycolates of $\boldsymbol{R}$-glycerol

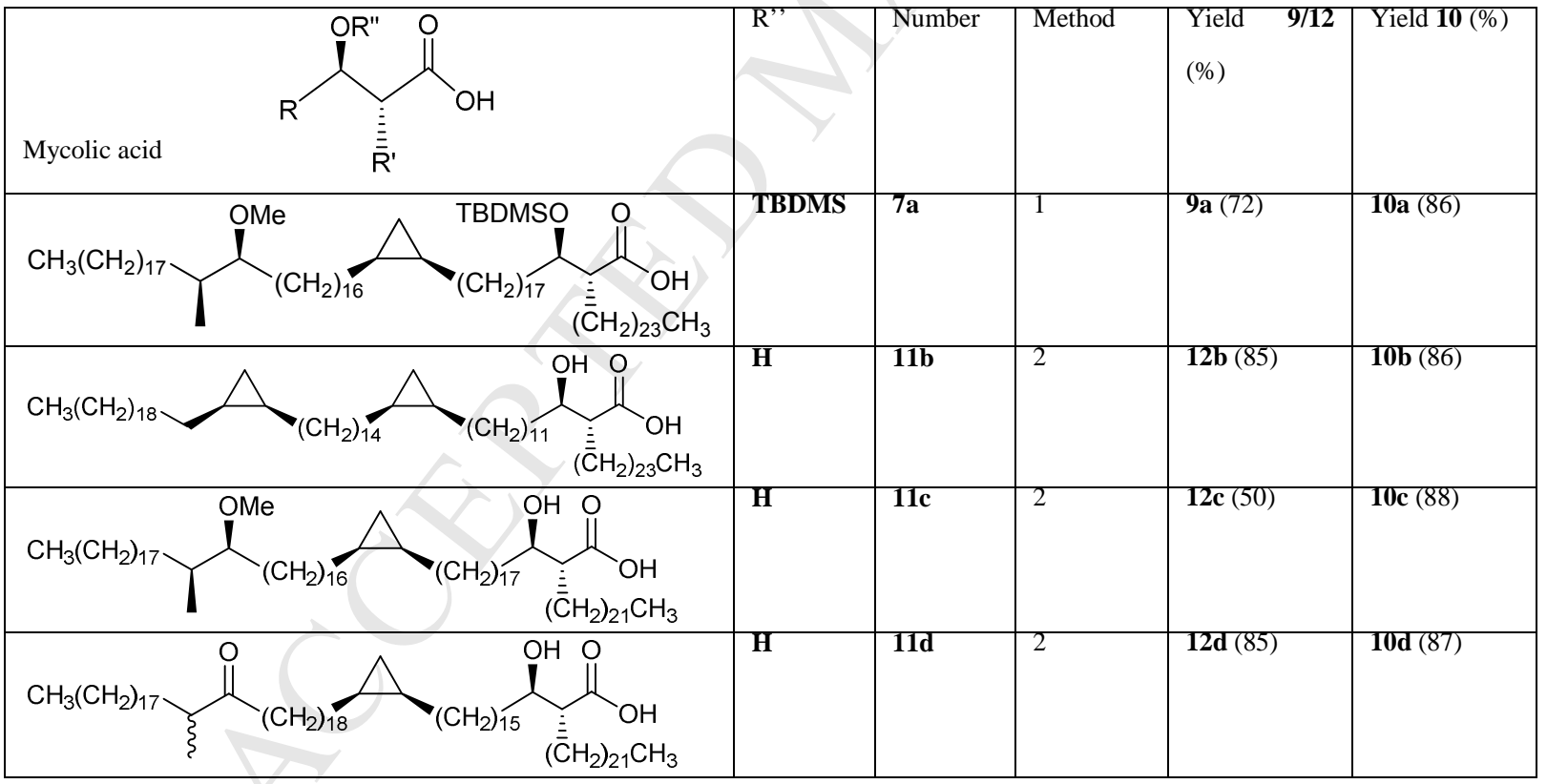

The $S$-glycerol mycolate esters were prepared by a modified method in which the glycerol was protected by benzyl groups, which, after coupling, were removed by hydrogenolysis: 


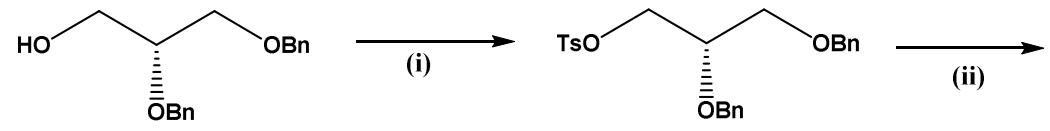

13

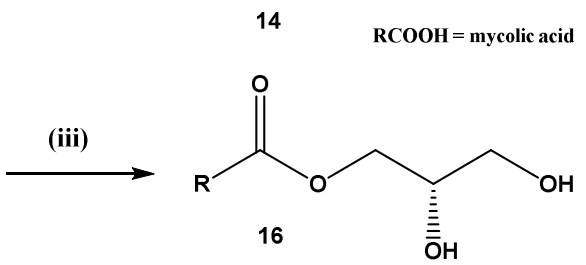

Scheme 3: (i) TsCl, py; (ii) $\mathrm{RCOOH}, \mathrm{CsHCO}_{3}$; (iii) $\mathrm{Pd}(\mathrm{OH})_{2}, \mathrm{H}_{2}, \mathrm{CH}_{2} \mathrm{Cl}_{2}, \mathrm{MeOH}$

Table 3. Synthetic mycolates of $S$-glycerol

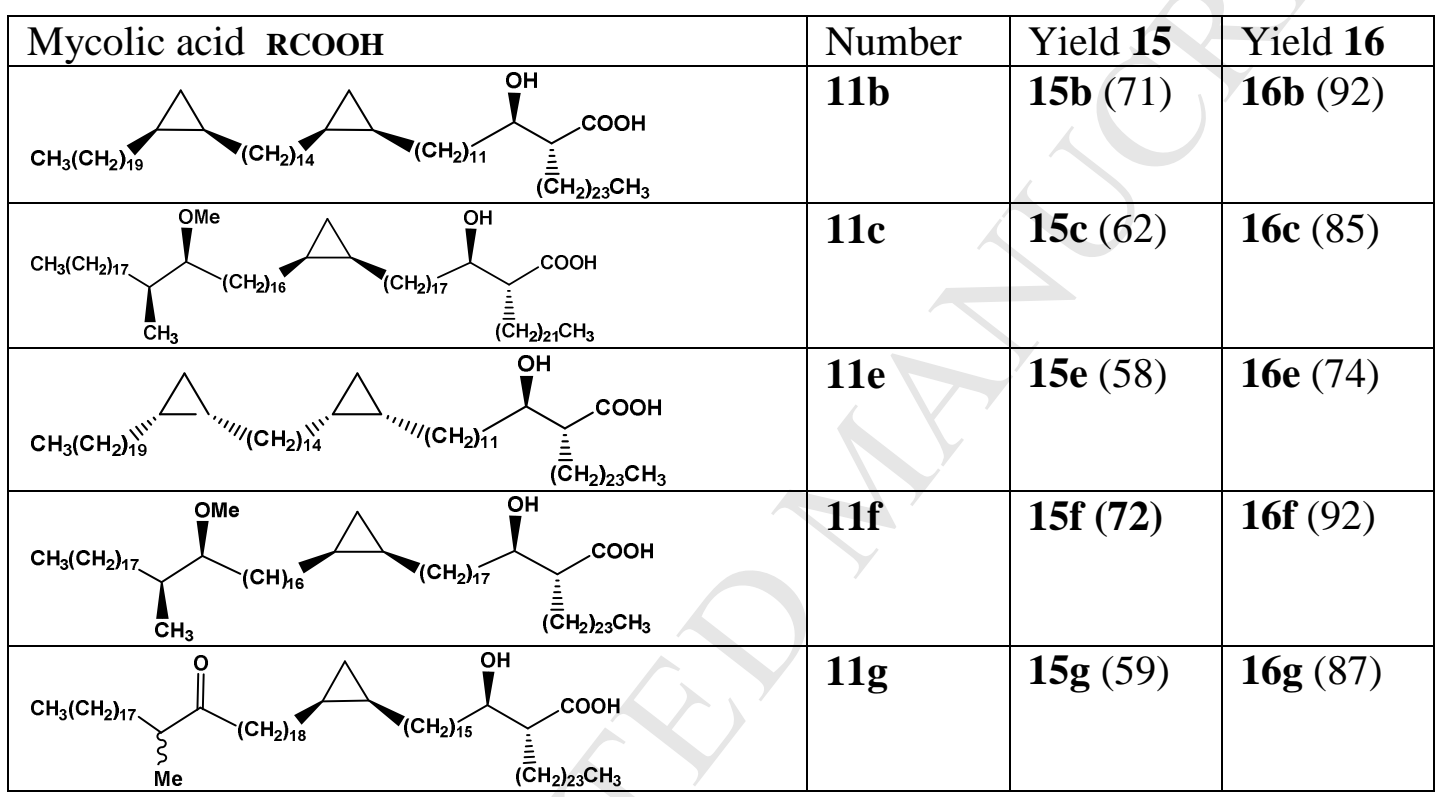

\section{Conclusion}

A set of nine R- and S-glycerol mycolates derived from single synthetic $\alpha$-, keto- and methoxy-mycolic acids are described. The GroMMs 10a-10d did not show any significant effects in the stimulation of cytokines in bone marrow dendritic cells (BMDCs) [28], unlike related TDMs and TMMs, GMMs and arabinose mycolates which activate BMDCs in terms of production of pro-inflammatory cytokines (IL- 6 and TNF- $\alpha$ ) and reactive oxygen species, upregulation of costimulatory molecules and activation of NLRP3 inflammasome by a mechanism dependent on Mincle [29]. However, they do show strong and selective effects in the stimulation of CD1b-restricted GEM $\mathrm{T}$ cell responses, mirroring the effects of the corresponding free mycolic acids [30].

\section{Experimental:}

\subsection{General considerations}


All chemicals were purchased from commercial suppliers. THF was distilled over sodium and benzophenone under nitrogen, while dichloromethane was distilled over calcium hydride. Petrol refers to the fraction b.p. $40-60{ }^{\circ} \mathrm{C}$. Organic solutions were dried over anhydrous magnesium sulfate. Reactions carried out under inert conditions were under a slow stream of nitrogen. Column chromatography and thin layer chromatography were carried out using Silica gel (Merck 7736, 40 - 63 micron) and silica gel plates (Merck, 60F254). $R_{f}$ values for the final GroMMs were all in the range $0.31-0.39$ using 20:1 chloroform/methanol. Infrared (IR) spectra were carried out on a Perkin-Elmer 1600 F.T.I.R. spectrometer as films or $\mathrm{KBr}$ discs or directly on a Bruker ALPHA FTIR spectrometer. Optical rotations were measured as solutions in chloroform using a Polar 2001 automatic polarimeter. NMR spectra were recorded either on an Advance 400 or 500 spectrometers. Spectra are reproduced in the Supplementary Information. Mass spectra were recorded on a Bruker matrix-assisted laser desorption/ionisation-time of flight mass spectrometry (MALDI-TOF MS) values are given plus sodium to an accuracy of 1 d.p. Accurate mass data were run by Dr Paul Gates (Bristol University) or the EPSRC UK National Mass Spectrometry Facility at Swansea University.

\section{$4.2 \quad((R)-2,3-D i h y d r o x y p r o p y l ~(R)-2-((R)-1-h y d r o x y-18-((1 R, 2 S)-2-((17 S, 18 S)-17-m e t h o x y-18-$ methylhexatriacontyl)cyclopropyl)octadecyl)hexacosanoate (10a)}

(a) $\quad(R)-2-((R)-1-(($ tert-Butyldimethylsilyl)oxy)-18-((1R,2S)-2-((17S,18S)-17-methoxy-18methylhexatriacontyl)cyclopropyl)octadecyl)hexacosanoic acid (7a) [31] (90 mg, $0.06 \mathrm{mmol}$ ) and DMAP (10 mg, $0.08 \mathrm{mmol}$ ) were added to a stirred solution of $(S)$-(2,2-dimethyl-1,3dioxolan-4-yl)methanol [32] (10 mg, $0.07 \mathrm{mmol})$ in $\mathrm{CH}_{2} \mathrm{Cl}_{2}(2 \mathrm{~mL})$. A solution of DCC (20 $\mathrm{mg} ; 0.09 \mathrm{mmol})$ in $\mathrm{CH}_{2} \mathrm{Cl}_{2}(2 \mathrm{~mL})$ was added dropwise with stirring under nitrogen over 120 min then stirred for $1 \mathrm{~h}$ at room temperature. Precipitated dicyclohexyl urea was filtered off and washed with dichloromethane $(10 \mathrm{~mL})$. The solvent was evaporated and the crude product was purified by column chromatography eluting with petrol/ethyl acetate (20:1) to give a semi-solid, compound 9a $(70 \mathrm{mg}, 72 \%),[\alpha]_{D}^{24}-6.7\left(c 1.4, \mathrm{CHCl}_{3}\right)$, [Found $(\mathrm{M}+\mathrm{Na})^{+}$: 1505.5, $\mathrm{C}_{97} \mathrm{H}_{192} \mathrm{NaO}_{6} \mathrm{Si}$ requires: 1504.4$]$, which showed $\delta_{\mathrm{H}}\left(500 \mathrm{MHz}, \mathrm{CDCl}_{3}\right): 4.33-4.26$ $(1 \mathrm{H}, \mathrm{m}), 4.11(1 \mathrm{H}, \mathrm{dd}, J 2.4,5.4 \mathrm{~Hz}), 4.06(1 \mathrm{H}, \mathrm{dd}, J 6.4,8.4 \mathrm{~Hz}), 3.94-3.87(1 \mathrm{H}, \mathrm{m}), 3.75$ $(1 \mathrm{H}, \mathrm{dd}, J 6.0,8.4 \mathrm{~Hz}), 3.34(3 \mathrm{H}, \mathrm{s}), 3.24-3.15(1 \mathrm{H}, \mathrm{m}), 2.98-2.92(1 \mathrm{H}, \mathrm{m}), 2.55(1 \mathrm{H}, \mathrm{ddd}$, $J 3.8,6.9,10.8 \mathrm{~Hz}), 2.00-1.01((153 \mathrm{H}, \mathrm{m}$ including two singlets at $1.43(3 \mathrm{H}, \mathrm{s})$ and 1.36 $(3 \mathrm{H}, \mathrm{s})), 0.91-0.83(18 \mathrm{H}$, including $\mathrm{d}$ for the methyl group $(\mathrm{J} 7 \mathrm{~Hz})$ and a $\mathrm{t}(\mathrm{J} 6.8 \mathrm{~Hz})$ for the terminal methyl group and s for the tert-butyl group), $0.69-0.61(2 \mathrm{H}, \mathrm{m}), 0.56(1 \mathrm{H}, \mathrm{dt}, J 3.7$, $7.6 \mathrm{~Hz}), 0.04(3 \mathrm{H}, \mathrm{s}), 0.01(3 \mathrm{H}, \mathrm{s}),-0.34(1 \mathrm{H}, \mathrm{q}, J 5.2 \mathrm{~Hz}) ; \delta_{\mathrm{C}}\left(126 \mathrm{MHz}, \mathrm{CDCl}_{3}\right): 174.7$, $109.8,85.6,73.7,66.8,64.4,57.9,55.9,51.6,35.5,35.1,34.0,32.6,32.1,30.7,30.4,30.2$, $30.1,29.9,29.8,29.6,29.5,28.9,28.0,27.7,26.9,26.3,26.2,25.9,25.6,25.5,24.9,24.1$, $22.9,18.1,15.9,15.0,14.3,11.1,-4.2,-4.7 ; v_{\max } / \mathrm{cm}^{-1}: 2918,2849,1726,1465,1256,1178$.

(b)Trifluoroacetic acid in dichloromethane $(1: 1,0.4 \mathrm{~mL})$ was added to a stirred solution of ester (9a) $(50 \mathrm{mg}, 0.03 \mathrm{mmol})$ in $\mathrm{CH}_{2} \mathrm{Cl}_{2}(2 \mathrm{~mL})$ at $0{ }^{\circ} \mathrm{C}$. The solution was stirred at $0{ }^{\circ} \mathrm{C}$ for $12 \mathrm{~h}$, when TLC showed no starting material was left and the reaction mixture was worked up by quenching with sat. aq. $\mathrm{NaHCO}_{3}(20 \mathrm{~mL})$ and the product was extracted with $\mathrm{CH}_{2} \mathrm{Cl}_{2}(2 \times$ 
$10 \mathrm{~mL}$ ) and the combined organic layers were dried and evaporated. The crude product was purified by column chromatography eluting with chloroform/methanol (15:1) to give a semisolid, the title compound (10a) $(40 \mathrm{mg}, 86 \%),[\alpha]_{D}^{23}-8.4\left(c 1.1, \mathrm{CHCl}_{3}\right)$, [MALDI-Found $(\mathrm{M}+\mathrm{Na})^{+}:$1350.3199, $\mathrm{C}_{88} \mathrm{H}_{174} \mathrm{NaO}_{6}$ requires: 1350.3203$]$, which showed $\delta_{\mathrm{H}}(500 \mathrm{MHz}$, $\left.\mathrm{C}_{6} \mathrm{D}_{6}\right): 4.25(1 \mathrm{H}, \mathrm{dd}, J 6.6,11.4, \mathrm{~Hz}), 4.12(1 \mathrm{H}, \mathrm{dd}, J 3.9,11.4, \mathrm{~Hz}), 3.81-3.71(2 \mathrm{H}, \mathrm{m}), 3.47$ $(1 \mathrm{H}, \mathrm{dd}, J 4.2,11.3, \mathrm{~Hz}), 3.40(1 \mathrm{H}, \mathrm{dd}, J 5.5,11.4, \mathrm{~Hz}), 3.27(3 \mathrm{H}, \mathrm{s}), 3.03-2.97(1 \mathrm{H}, \mathrm{m})$, $2.55(1 \mathrm{H}, \mathrm{dd}, J$ 9.0, 12.5, Hz), 1.9-1.25 $(149 \mathrm{H}, \mathrm{m}), 1.00(3 \mathrm{H}, \mathrm{d}, J 6.8 \mathrm{~Hz}), 0.93(7 \mathrm{H}$, including t, $J 6.6 \mathrm{~Hz}), 0.78-0.71(2 \mathrm{H}, \mathrm{m}), 0.68(1 \mathrm{H}, \mathrm{dt}, J 3.7,7.6 \mathrm{~Hz}),-0.01(1 \mathrm{H}, \mathrm{q}, J 5.0 \mathrm{~Hz}) ; \delta_{\mathrm{C}}(126$ $\left.\mathrm{MHz}, \mathrm{C}_{6} \mathrm{D}_{6}\right): 175.2,85.4,73.2,70.4,65.5,63.6,57.6,53.0,35.9,35.8,33.0,32.4,30.9,30.8$, $30.6,30.5,30.3,30.2,30.1,30.0,29.9,29.8,29.3,28.2,28.0,26.7,26.0,23.1,16.3,15.3$, $14.4,11.5 ; v_{\max } / \mathrm{cm}^{-1}: 34992928,2854,1744,1435,1267,1178$.

\section{3 (R)-2,3-Dihydroxypropyl $(R)-2-((R)-1$-hydroxy-12-((1R,2S)-2-(14-((1R,2S)-2-eicosyl- cyclopropyl)tetradecyl)cyclopropyl)dodecyl) hexacosanoate (10b)}

(a) Dry cesium hydrogen carbonate $(120 \mathrm{mg}, 0.33 \mathrm{mmol})$ was added to a stirred solution of acid (11b) [33] (70 mg, $0.06 \mathrm{mmol})$ in a mixture of THF:DMF $(1: 1,4 \mathrm{~mL})$ at room temperature. The mixture was left at room temperature for $1 \mathrm{~h}$ then $(R)$-(2,2-dimethyl-1,3dioxolan-4-yl)methyl 4-methylbenzenesulfonate 2 [34] (40 mg, $0.13 \mathrm{mmol}$ ) was added. The mixture was brought to $70{ }^{\circ} \mathrm{C}$ and left at this temperature for $18 \mathrm{~h}$, then cooled to room temperature and diluted with ethyl acetate $(15 \mathrm{~mL})$. The organic layer washed twice with water, dried and concentrated. Column chromatography eluting with petrol/ethyl acetate $(5: 1)$ gave a semi-solid, title compound (12b) (66 mg, 85\%), $[\alpha]_{D}^{20}-4.7$ (c 1.2, $\left.\mathrm{CHCl}_{3}\right)$, [Found $(\mathrm{M}+\mathrm{Na})^{+}: 1274.2, \mathrm{C}_{84} \mathrm{H}_{162} \mathrm{O}_{5} \mathrm{Na}$ requires: 1274.2$]$. This showed $\delta_{\mathrm{H}}\left(400 \mathrm{MHz}, \mathrm{CDCl}_{3}\right): 4.27-$ $4.20(1 \mathrm{H}, \mathrm{m}), 4.10(1 \mathrm{H}, \mathrm{dd}, J 3.3,9.9 \mathrm{~Hz}), 4.06(1 \mathrm{H}, \mathrm{dd}, J 4.3,9.9 \mathrm{~Hz}), 3.97(1 \mathrm{H}, \mathrm{dd}, J 6.5$, $8.5 \mathrm{~Hz}), 3.65(1 \mathrm{H}, \mathrm{dd}, J 5.9,8.5 \mathrm{~Hz}), 3.56(1 \mathrm{H}, \mathrm{br} \mathrm{s}), 2.41-2.28(2 \mathrm{H}, \mathrm{m}), 1.38-0.98$ $((140 \mathrm{H}, \mathrm{m}$ including $1.34(3 \mathrm{H}, \mathrm{s}), 1.26(3 \mathrm{H}, \mathrm{s})), 0.78(6 \mathrm{H}, \mathrm{t}, J 6.8), 0.61-0.50(4 \mathrm{H}, \mathrm{m}), 0.50$ $-0.41(2 \mathrm{H}, \mathrm{m}),-0.43(2 \mathrm{H}, \mathrm{q}, J 5.2 \mathrm{~Hz}) ; \delta_{\mathrm{C}}\left(101 \mathrm{MHz}, \mathrm{CDCl}_{3}\right): 175.3,109.8,73.4,72.3,66.3$, 64.4, 51.3, 35.6, 31.9, 30.2, 29.73, 29.7, 29.6, 29.5, 29.4, 28.7, 27.4, 26.7, 25.7, 25.3, 22.7, 15.7, 14.1, 10.9; $v_{\max } / \mathrm{cm}^{-1}: 3430,3011,2925,2886,1744,1232,759,669$.

(b) Hydrochloric acid (2 M, $0.04 \mathrm{~mL}$ ) was added to a stirred solution of ester (12b) $(55 \mathrm{mg}$, $0.04 \mathrm{mmol})$ in THF $(25 \mathrm{~mL})$ at room temperature, then stirred at $40{ }^{\circ} \mathrm{C}$ for $16 \mathrm{~h}$. The mixture was quenched at room temperature with sat. aq. $\mathrm{NaHCO}_{3}(10 \mathrm{~mL})$, the product was extracted with $\mathrm{CH}_{2} \mathrm{Cl}_{2}(25 \mathrm{~mL})$ and the aqueous phase was re-extracted with $\mathrm{CH}_{2} \mathrm{Cl}_{2}(3 \times 25)$. The organic extracts were dried and concentrated. The crude residue was purified by column chromatography eluting with petrol/ethyl acetate (4:1) to give a semi-solid, the title compound (10b) (46 mg, 86\%), $[\alpha]_{D}^{22}-6.5\left(c \quad 0.90, \mathrm{CHCl}_{3}\right)$ [MALDI-Found $(\mathrm{M}+\mathrm{Na})^{+}$: 1234.2005, $\mathrm{C}_{81} \mathrm{H}_{158} \mathrm{NaO}_{5}$ requires: 1234.2001$]$, which showed $\delta_{\mathrm{H}}\left(400 \mathrm{MHz}, \mathrm{CDCl}_{3}\right): 4.30$ $4.26(2 \mathrm{H}, \mathrm{m}), 4.01-3.95(1 \mathrm{H}, \mathrm{m}), 3.76-3.61(3 \mathrm{H}, \mathrm{m}), 2.54-2.44(1 \mathrm{H}, \mathrm{m}), 1.49-1.08$ $(137 \mathrm{H}, \mathrm{m}), 0.90(6 \mathrm{H}, \mathrm{t}, J 6.8 \mathrm{~Hz}), 0.71-0.63(4 \mathrm{H}, \mathrm{m}), 0.58(2 \mathrm{H}, \mathrm{dt}, J 3.7,7.6 \mathrm{~Hz}),-0.31(2 \mathrm{H}$, q, $J 5.2 \mathrm{~Hz}) ; \delta_{\mathrm{C}}\left(101 \mathrm{MHz}, \mathrm{CDCl}_{3}\right): 175.6,73.1,70.1,65.4,63.4,52.3,35.5,32.1,30.4,29.9$, $29.8,29.7,29.6,29.5,29.5,28.9,27.6,25.6,22.8,15.9,14.3,11.1 ; v_{\max } / \mathrm{cm}^{-1}: 3430,3011$, 2925, 2886,1744, 1232, 759, 669. 
4.4 (R)-2,3-Dihydroxypropyl $(R)-2-((R)-1$-hydroxy-18- $((1 R, 2 S)-2-((17 S, 18 S)-17-m e t h o x y-$ 18-methylhexatriacontyl)cyclopropyl)octadecyl)tetracosanoate (10c)

(a) Dry cesium hydrogen carbonate $(100 \mathrm{mg}, 0.40 \mathrm{mmol}$ ) was added to a stirred solution of acid (11c) [36] (70 mg, $0.05 \mathrm{mmol})$ in a mixture of THF:DMF (1:1, $2 \mathrm{~mL})$ at room temperature. The mixture was left at room temperature for $1 \mathrm{~h}$ then $(R)$-tosylate $(2)(80 \mathrm{mg}$, $0.2 \mathrm{mmol}$ ) was added. The mixture was heated at $70{ }^{\circ} \mathrm{C}$ for $18 \mathrm{~h}$, then worked up and purified as before to give a semi-solid, compound (12c) $(70 \mathrm{mg}, 50 \%),[\alpha]_{D}^{21}-6.2(c 0.90$, $\mathrm{CHCl}_{3}$ ) [Found $(\mathrm{M}+\mathrm{Na})^{+}: 1362.5, \mathrm{C}_{89} \mathrm{H}_{174} \mathrm{NaO}_{6}$ requires: 1362.3 ]; $\delta_{\mathrm{H}}\left(400 \mathrm{MHz}, \mathrm{CDCl}_{3}\right)$ : $4.37-4.29(1 \mathrm{H}, \mathrm{m}), 4.20(1 \mathrm{H}, \mathrm{dd}, J 3.3,9.9 \mathrm{~Hz}), 4.16(1 \mathrm{H}, \mathrm{dd}, J 2.4,8.0 \mathrm{~Hz}), 4.07(1 \mathrm{H}, \mathrm{dd}, J$ 6.5, $8.5 \mathrm{~Hz}), 3.75(1 \mathrm{H}, \mathrm{dd}, J$ 5.9, $8.4 \mathrm{~Hz}), 3.66(1 \mathrm{H}$, br s), $3.34(3 \mathrm{H}, \mathrm{s}), 2.99-2.92(1 \mathrm{H}, \mathrm{m})$, $2.52-2.37(2 \mathrm{H}, \mathrm{m}), 1.48-1.06((149 \mathrm{H}, \mathrm{m}$ including $1.44(3 \mathrm{H}, \mathrm{s}), 1.36(3 \mathrm{H}, \mathrm{s})), 0.88(6 \mathrm{H}, \mathrm{t}$, $J 6.8 \mathrm{~Hz}), 0.85(3 \mathrm{H}, \mathrm{d}, J 6.9 \mathrm{~Hz}), 0.64(2 \mathrm{H}, \mathrm{br} \mathrm{s}), 0.60-0.51(1 \mathrm{H}, \mathrm{m}),-0.34(1 \mathrm{H}, \mathrm{q}, J 5.3 \mathrm{~Hz})$; $\delta_{\mathrm{C}}\left(101 \mathrm{MHz}, \mathrm{CDCl}_{3}\right): 175.3,109.8,85.5,73.4,72.3,66.3,64.4,57.7,51.3,35.5,35.3,32.4$, $31.9,30.8,30.2,30.0,29.9,29.7,29.6,29.5,29.4,29.3,28.7,27.6,27.4,26.7,26.1,25.7$, 25.3, 22.7, 15.8, 14.9, 14.1, 10.9; $v_{\max } / \mathrm{cm}^{-1}: 3511,2918,2849,1726,1465,1256,1178$.

(b) Hydrochloric acid (2 M, $0.04 \mathrm{~mL})$ was added with stirring to ester (12c) $(65 \mathrm{mg}$, $0.05 \mathrm{mmol})$ in THF $(34 \mathrm{ml})$ at room temperature. The mixture was stirred at $40{ }^{\circ} \mathrm{C}$ for $16 \mathrm{~h}$, then worked up and purified as before to give a semi-solid, the title compound (10c) $(56 \mathrm{mg}$, $88 \%),[\alpha]_{D}^{24}-9.3\left(c\right.$ 1.2, $\left.\mathrm{CHCl}_{3}\right)$ [MALDI-Found $(\mathrm{M}+\mathrm{Na})^{+}: 1322.2880, \mathrm{C}_{86} \mathrm{H}_{170} \mathrm{NaO}_{6}$ requires: 1322.2890$] ; \delta_{\mathrm{H}}\left(500 \mathrm{MHz}, \mathrm{CDCl}_{3}\right): 4.30-4.22(2 \mathrm{H}, \mathrm{m}), 3.99-3.92(1 \mathrm{H}, \mathrm{m}), 3.74-$ $3.67(2 \mathrm{H}, \mathrm{m}), 3.62(1 \mathrm{H}, \mathrm{dd}, J 5.5,11.4 \mathrm{~Hz}), 3.34(3 \mathrm{H}, \mathrm{s}), 2.98-2.92(1 \mathrm{H}, \mathrm{m}), 2.50-2.42$ $(1 \mathrm{H}, \mathrm{m}), 1.74-1.01(146 \mathrm{H}, \mathrm{m}), 0.88(6 \mathrm{H}, \mathrm{t}, J 6.9 \mathrm{~Hz}), 0.84(3 \mathrm{H}, \mathrm{d}, J 6.9 \mathrm{~Hz}), 0.69-0.60$ $(2 \mathrm{H}, \mathrm{m}), 0.55(1 \mathrm{H}, \mathrm{dt}, J 3.9,8.4 \mathrm{~Hz}),-0.34(1 \mathrm{H}, \mathrm{q}, J 5.1 \mathrm{~Hz}) ; \delta_{\mathrm{C}}\left(101 \mathrm{MHz}, \mathrm{CDCl}_{3}\right): 175.6$, 85.6, 73.1, 70.1, 65.4, 63.4, 57.9, 52.3, 35.5, 35.4, 34.1, 32.5, 32.1, 30.6, 30.4, 30.1, 30.0, 29.9, 29.8, 29.7, 29.6, 29.5, 28.9, 27.7, 27.6, 26.3, 25.6, 25.1, 22.8, 15.9, 15.0, 14.3, 11.1; $v_{\max } / \mathrm{cm}^{-1}: 3511,2918,2849,1726,1465,1256,1178$.

\section{$4.5(R)-2,3-D i h y d r o x y p r o p y l \quad(2 R)-2-((1 R)-1-h y d r o x y-16-((1 R, 2 S)-2-(20-m e t h y l-19-0 x o-$ octatriacontyl)cyclopropyl)hexadecyl)tetracosanoate (10d)}

(a) Dry cesium hydrogen carbonate $(110 \mathrm{mg}, 0.50 \mathrm{mmol})$ was added to a stirred solution of acid (11d) [36] (80 mg, $0.06 \mathrm{mmol})$ in a mixture of THF:DMF (1:1, $3 \mathrm{~mL})$ at room temperature. The mixture was stirred for $1 \mathrm{~h}$ then $R$-tosylate (2) $(40 \mathrm{mg}, 0.13 \mathrm{mmol})$ was added .The mixture was brought to $70{ }^{\circ} \mathrm{C}$ and left at this temperature for $18 \mathrm{~h}$, then worked up and purified as before to give a semi-solid, compound (12d) $(64 \mathrm{mg}, 85 \%),[\alpha]_{D}^{24}-8.1(c$ $\left.1.4, \mathrm{CHCl}_{3}\right)$ [Found $(\mathrm{M}+\mathrm{Na})^{+}: 1346.9, \mathrm{C}_{88} \mathrm{H}_{170} \mathrm{NaO}_{6}$ requires: 1346.3], which showed $\delta_{\mathrm{H}}(400$ $\left.\mathrm{MHz}, \mathrm{CDCl}_{3}\right): 4.40-4.32(1 \mathrm{H}, \mathrm{m}), 4.26(1 \mathrm{H}, \mathrm{dd}, J 5.9,11.4 \mathrm{~Hz}), 4.20(1 \mathrm{H}, \mathrm{dd}, J 2.2,5.4$ $\mathrm{Hz}), 4.14(1 \mathrm{H}, \mathrm{dd}, J 4.6,11.4 \mathrm{~Hz}), 4.12-4.07(1 \mathrm{H}, \mathrm{m}), 3.78(1 \mathrm{H}$, ddd, $J 2.3,5.7,8.3 \mathrm{~Hz})$, $3.73-3.65(1 \mathrm{H}, \mathrm{m}), 2.57-2.40(4 \mathrm{H}, \mathrm{m}), 1.66-1.11((146 \mathrm{H}, \mathrm{m}$ including $1.46(3 \mathrm{H}, \mathrm{s}), 1.38$ $(3 \mathrm{H}, \mathrm{s})), 1.07(3 \mathrm{H}, \mathrm{d}, J 6.9 \mathrm{~Hz}), 0.90(6 \mathrm{H}, \mathrm{t}, J 6.8 \mathrm{~Hz}), 0.71-0.63(2 \mathrm{H}, \mathrm{m}), 0.62-0.54(1 \mathrm{H}$, $\mathrm{m}),-0.31(1 \mathrm{H}, \mathrm{q}, J 5.2 \mathrm{~Hz}) ; \delta_{\mathrm{C}}\left(101 \mathrm{MHz}, \mathrm{CDCl}_{3}\right): 215.2,175.3,109.8,73.5,72.3,66.2,64.6$, 51.5, 46.3, 41.1, 35.6, 35.5, 33.0, 31.9, 30.2, 29.7, 29.59, 29.5, 29.3, 28.7, 27.3, 26.7, 25.3, 23.7, 22.7, 16.3, 15.7, 14.1, 10.9; $v_{\max } / \mathrm{cm}^{-1}: 3455,2944,2861,1722,1146,1382,1214$, 1022 . 
(b) Hydrochloric acid (2 M, $0.04 \mathrm{~mL})$ was added to a stirred solution of ester (12d) $(60 \mathrm{mg}$, $0.04 \mathrm{mmol})$ in THF $(30 \mathrm{~mL})$ at room temperature. The mixture was stirred was at $40{ }^{\circ} \mathrm{C}$ for $16 \mathrm{~h}$. then worked up and purified as before to give a semi-solid, the title compound (10d) $(51 \mathrm{mg}, \quad 87 \%),[\alpha]_{D}^{22}-12$ (c 1.1, $\left.\mathrm{CHCl}_{3}\right) \quad\left[\mathrm{MALDI}-\mathrm{Found}(\mathrm{M}+\mathrm{Na})^{+}:\right.$1306.2569, $\mathrm{C}_{85} \mathrm{H}_{166} \mathrm{NaO}_{6}$ requires: 1306.2577], which showed $\delta_{\mathrm{H}}\left(400 \mathrm{MHz}, \mathrm{CDCl}_{3}\right): 4.30(1 \mathrm{H}, \mathrm{dd}, J$ 4.1, $11.8 \mathrm{~Hz}), 4.25(1 \mathrm{H}, \mathrm{dd}, J 6.7,11.8 \mathrm{~Hz}), 4.03-3.94(1 \mathrm{H}, \mathrm{m}), 3.77-3.70(2 \mathrm{H}, \mathrm{m}), 3.65$ $(1 \mathrm{H}, \mathrm{dd}, J 4.6,10.5 \mathrm{~Hz}), 2.57-2.39(4 \mathrm{H}, \mathrm{m}), 1.76-1.10(143 \mathrm{H}, \mathrm{m}), 1.07(3 \mathrm{H}, \mathrm{d}, J 6.9 \mathrm{~Hz})$, $0.90(6 \mathrm{H}, \mathrm{t}, J 6.8 \mathrm{~Hz}), 0.66(2 \mathrm{H}, \mathrm{br} \mathrm{s}), 0.58(1 \mathrm{H}, \mathrm{dt}, J 3.7,7.8 \mathrm{~Hz}),-0.31(1 \mathrm{H}, \mathrm{q}, J 5.2 \mathrm{~Hz}) ; \delta_{\mathrm{C}}$ (101 MHz, $\left.\mathrm{CDCl}_{3}\right)$ : 215.3, 175.4, 72.9, 69.7, 65.2, 63.3, 52.2, 46.3, 41.1, 37.9, 35.3, 33.0, $31.9,30.2,29.7,29.6,29.5,29.4,29.3,29.2,28.7,27.4,27.3,25.5,23.7,22.7,16.3,15.8$, $14.1,10.9 ; v_{\max } / \mathrm{cm}^{-1}: 3455,2944,2861,1722,1146,1382,1214,1022$.

\section{6 (S)-2,3-Bis(benzyloxy)propyl alkanoate (15): General procedure}

Cesium hydrogen carbonate was added to a stirred solution of 1-O-p-toluene-sulfonyl- $(S)$ 2,3-di- $O$-benzylglycerol (14) [37], and acid in dry DMF:THF (1:5, $2 \mathrm{~mL}$ ) at room temperature. The mixture was stirred at $70{ }^{\circ} \mathrm{C}$ for 2 days, then diluted with ethyl acetate (10 $\mathrm{mL})$ and water $(10 \mathrm{~mL})$. The organic layer was separated and the aqueous layer was reextracted with ethyl acetate $(3 \times 10 \mathrm{~mL})$. The combined organic layers were washed successively with water $(15 \mathrm{~mL})$ and brine $(15 \mathrm{~mL})$, dried and evaporated. The residue was purified by column chromatography.

\section{7 (S)-2,3-Dihydroxypropyl alkanoate (16): General procedure}

Palladium hydroxide on activated charcoal (20\% Pd, 0.15 fold by weight) was stirred with compounds (15) in dry $\mathrm{CH}_{2} \mathrm{Cl}_{2}: \mathrm{MeOH}(1: 1,2 \mathrm{~mL})$ at room temperature under hydrogen. The mixture was stirred for $24 \mathrm{~h}$ then filtered through celite. The celite was washed with $\mathrm{CH}_{2} \mathrm{Cl}_{2}(10 \mathrm{~mL})$, the filtrate was evaporated, and the residue purified by column chromatography.

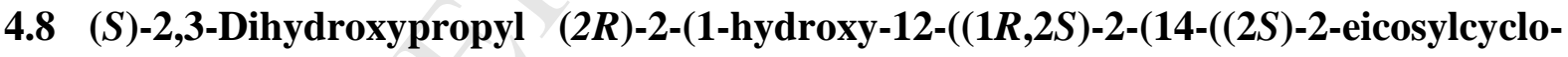 propyl)tetradecyl)cyclopropyl)dodecyl)hexacosanoate (16b)}


(a) Cesium hydrogen carbonate $(0.0616 \mathrm{~g}, 0.317 \mathrm{mmol})$, tosylate (14) $(0.0298 \mathrm{~g}, 0.0698$ $\mathrm{mmol}$ ) and the acid (11b) [33] (0.0724 g, $0.0636 \mathrm{mmol})$ gave a thick colourless oil; column chromatography (hexane/ethyl acetate, 10:1) gave compound (15b), (62 mg, 71\%); $[\alpha]_{D}^{22}$ +3.8 $\left(c 0.31, \mathrm{CHCl}_{3}\right) ; \delta_{\mathrm{H}}\left(400 \mathrm{MHz}, \mathrm{CDCl}_{3}\right): 7.35-7.27(10 \mathrm{H}, \mathrm{m}), 4.68(1 \mathrm{H}, \mathrm{d}, J 11.8 \mathrm{~Hz})$, $4.65(1 \mathrm{H}, \mathrm{d}, J 11.8 \mathrm{~Hz}), 4.55(2 \mathrm{H}$, br.s), $4.43(1 \mathrm{H}, \mathrm{dd}, J 4.1,11.7 \mathrm{~Hz}), 4.22(1 \mathrm{H}, \mathrm{dd}, J 5.5$, $11.7 \mathrm{~Hz}), 3.86-3.80(1 \mathrm{H}, \mathrm{m}), 3.67-3.55(3 \mathrm{H}$, including br dd $J 1.6,5.4 \mathrm{~Hz}$ at $\delta 3.6), 2.45$ $(1 \mathrm{H}, \mathrm{d}, J 8.0 \mathrm{~Hz}), 2.43(1 \mathrm{H}, \mathrm{br} . \mathrm{dd}, J 3.8,10.5 \mathrm{~Hz}), 1.80-1.00(134 \mathrm{H}, \mathrm{m}), 0.89(6 \mathrm{H}, \mathrm{t}, J 6.7$ $\mathrm{Hz}), 0.71-0.61(4 \mathrm{H}, \mathrm{m}), 0.57(2 \mathrm{H}, \mathrm{dt}, J 3.9,8.4 \mathrm{~Hz}),-0.32(2 \mathrm{H}$, br.q, $J 5.2 \mathrm{~Hz}) ; \delta_{\mathrm{C}}(101$ $\left.\mathrm{MHz}, \mathrm{CDCl}_{3}\right)$ : 175.4, 138.0, 137.9, 128.4, 128.3, 127.8, 127.7, 127.6, 75.8, 73.5, 72.3, 72.1, $69.6,63.5,51.4,35.5,31.9,30.2,29.7,29.6,29.5,29.4,29.3,28.7,27.5,25.8,23.0,15.8$, 14.1, 10.9; $v_{\max }$ : 2991, 2917, 2850, 1732, 1599, $1469 \mathrm{~cm}^{-1}$.

(b) Palladium hydroxide on activated charcoal $(0.0077 \mathrm{~g})$ and ester (15b) $(0.0515 \mathrm{~g}, 0.0369$ mmol) gave a thick colourless oil; column chromatography (chloroform /methanol, 10:1) gave the title compound (16b) (40 mg, 92\%) [MALDI-Found $(\mathrm{M}+\mathrm{Na})^{+}:$1234.2001, $\mathrm{C}_{81} \mathrm{H}_{158} \mathrm{NaO}_{5}$, requires: 1234.2007$] ;[\alpha]_{D}^{22}+1.8\left(c 0.34, \mathrm{CHCl}_{3}\right) ; \delta_{\mathrm{H}}\left(400 \mathrm{MHz}, \mathrm{CDCl}_{3}+\right.$ few drops of $\left.\mathrm{CD}_{3} \mathrm{OD}\right): 4.21(1 \mathrm{H}, \mathrm{dd}, J 4.3,11.4 \mathrm{~Hz}), 4.10(1 \mathrm{H}, \mathrm{dd}, J 6.4,11.5 \mathrm{~Hz}), 3.89-3.80$ $(1 \mathrm{H}, \mathrm{m}), 3.60(2 \mathrm{H}, \mathrm{br} \mathrm{dd}, J 4.1,11.5 \mathrm{~Hz}), 3.54(1 \mathrm{H}, \mathrm{dd}, J 5.8,11.6 \mathrm{~Hz}), 2.39(1 \mathrm{H}, \mathrm{ddd}, J 4.8$, 7.6, $10.0 \mathrm{~Hz}), 1.86-0.94(137 \mathrm{H}, \mathrm{m}), 0.84(6 \mathrm{H}, \mathrm{t}, J 6.8 \mathrm{~Hz}), 0.65-0.56(4 \mathrm{H}, \mathrm{m}), 0.52(2 \mathrm{H}$, dt, $J 3.9,8.5 \mathrm{~Hz}),-0.37(2 \mathrm{H}$, br.q, $J 4.9 \mathrm{~Hz}) ; \delta_{\mathrm{C}}\left(101 \mathrm{MHz}, \mathrm{CDCl}_{3}+\right.$ few drops of $\left.\mathrm{CD}_{3} \mathrm{OD}\right)$ : $175.5,72.6,69.8,65.1,63.0,52.5,37.0,35.0,31.8,30.1,29.6,29.55,29.5,29.45,29.4,29.3$, $29.2,28.6,27.4,25.3,22.6,15.7,14.0,10.8 ; v_{\max }: 3585,2917,2849,1734,1468 \mathrm{~cm}^{-1}$.

\section{9 (S)-2,3-Dihydroxypropyl $(R)-2-((R)-1-h y d r o x y-18-((1 R, 2 S)-2-((17 S, 18 S)-17-m e t h o x y-$ 18-methylhexatriacontyl)cyclopropyl)octadecyl)tetracosanoate (16c)}

(a) Cesium hydrogen carbonate $(0.0436 \mathrm{~g}, 0.225 \mathrm{mmol})$, tosylate (14) (0.0211 g, 0.0495 $\mathrm{mmol})$ and acid 11c $(0.0552 \mathrm{~g}, 0.0450 \mathrm{mmol})$ [36] gave a thick colourless oil which was purified by column chromatography (hexane/ethyl acetate, 10:1) to afford compound (15c), (41 mg, 62\%); $[\alpha]_{D}^{22}+9.0\left(c 0.31, \mathrm{CHCl}_{3}\right)$, which showed $\delta_{\mathrm{H}}\left(400 \mathrm{MHz}, \mathrm{CDCl}_{3}\right): 7.32-7.19$ $(10 \mathrm{H}, \mathrm{m}), 4.62(1 \mathrm{H}, \mathrm{d}, J 11.8 \mathrm{~Hz}), 4.58(1 \mathrm{H}, \mathrm{d}, J 11.8 \mathrm{~Hz}), 4.48(2 \mathrm{H}, \mathrm{br}), 4.36(1 \mathrm{H}, \mathrm{dd}, J$ 4.1, $11.7 \mathrm{~Hz}), 4.15(1 \mathrm{H}, \mathrm{dd}, J 5.5,11.7 \mathrm{~Hz}), 3.81-3.72(1 \mathrm{H}, \mathrm{m}), 3.60-3.49$ (3H, including br dd, J 1.6, 5.4 Hz, at 3.53), $3.28(3 \mathrm{H}, \mathrm{s}), 2.90(1 \mathrm{H}$, br.p, $J 4.1 \mathrm{~Hz}), 2.39(1 \mathrm{H}, \mathrm{d}, J 7.9 \mathrm{~Hz})$, $2.36(1 \mathrm{H}$, br.dd, $J 3.5,7.4 \mathrm{~Hz}), 1.75-0.93(143 \mathrm{H}, \mathrm{m}), 0.83(6 \mathrm{H}, \mathrm{t}, J 6.8 \mathrm{~Hz}), 0.79(3 \mathrm{H}, \mathrm{d}, J$ $6.9 \mathrm{~Hz}), 0.65-0.54(2 \mathrm{H}, \mathrm{m}), 0.50(1 \mathrm{H}, \mathrm{dt}, J 4.0,8.4 \mathrm{~Hz}),-0.39(1 \mathrm{H}$, br q, $J 5.2 \mathrm{~Hz}) ; \delta_{\mathrm{C}}$ $\left(101 \mathrm{MHz}, \mathrm{CDCl}_{3}\right): 175.3,137.9,137.8,128.3,128.2,127.7,127.6,127.5,85.3,75.7,73.4$, 72.2 , 72.0, 69.5, 63.4, 57.6, 51.3, 38.6, 35.4, 35.2, 32.3, 31.8, 30.4, 30.3, 30.1, 29.9, 29.8, $29.7,29.6,29.5,29.4,29.3,29.2,28.8,28.6,27.5,27.4,26.0,25.7,23.6,22.9,22.6,15.7$, 14.8, 14.0, 13.9, 10.9, 10.8; $v_{\max }: 2923,2853,1737,1465 \mathrm{~cm}^{-1}$.

(b) Palladium hydroxide on activated charcoal (0.0054 g) and ester (15c) (0.0364 g, $0.0245 \mathrm{mmol}$ ) gave a thick colourless oil; column chromatography (chloroform/methanol, 20:1) gave the title compound (16c) $(27 \mathrm{mg}, 85 \%)$; [MALDI-Found $(\mathrm{M}+\mathrm{Na})^{+}: 1322.2890$, $\mathrm{C}_{86} \mathrm{H}_{170} \mathrm{NaO}_{6}$, requires: 1322.2895$] ;[\alpha]_{D}^{23}+1.6$ (c 2.1, $\left.\mathrm{CHCl}_{3}\right) ; \delta_{\mathrm{H}}\left(400 \mathrm{MHz}, \mathrm{CDCl}_{3}+\right.$ few 
drops of $\left.\mathrm{CD}_{3} \mathrm{OD}\right): 4.21(1 \mathrm{H}, \mathrm{dd}, J 4.3,11.4 \mathrm{~Hz}), 4.11(1 \mathrm{H}, \mathrm{dd}, J 6.4,11.4 \mathrm{~Hz}), 3.88-3.82$ $(1 \mathrm{H}, \mathrm{m}), 3.66-3.57(2 \mathrm{H}$, including br dd, $J 4.3,11.4 \mathrm{~Hz}$ at $\delta 3.6), 3.54(1 \mathrm{H}, \mathrm{dd}, J 5.8,11.6$ Hz), 3.31 (3H, s), 2.94 (1H, br.p, J 4.4 Hz), 2.40 (1H, ddd, J 4.8, 7.4, $10.2 \mathrm{~Hz}), 1.81-0.94$ $(146 \mathrm{H}, \mathrm{m}), 0.84(6 \mathrm{H}, \mathrm{t}, J 7.0 \mathrm{~Hz}), 0.81(3 \mathrm{H}, \mathrm{d}, J 6.9 \mathrm{~Hz}), 0.65-0.57(2 \mathrm{H}, \mathrm{m}), 0.52(1 \mathrm{H}, \mathrm{dt}, J$ 4.0, $8.5 \mathrm{~Hz}),-0.37(1 \mathrm{H}$, br.q, J $5.1 \mathrm{~Hz}) ; \delta_{\mathrm{C}}\left(101 \mathrm{MHz}, \mathrm{CDCl}_{3}+\right.$ few drops of $\left.\mathrm{CD}_{3} \mathrm{OD}\right): 175.5$, 85.5, 72.6, 69.8, 65.1, 63.0, 57.6, 52.4, 35.3, 35.0, 32.3, 31.8, 30.4, 30.1, 29.9, 29.8, 29.7, $29.6,29.55,29.5,29.45,29.4,29.3,28.6,27.5,27.4,26.0,25.3,22.6,15.7,14.7,14.0,10.8$; $v_{\max }: 3368,2918,2850,1731,1467 \mathrm{~cm}^{-1}$.

\subsection{0 (S)-2,3-dihydroxypropyl $\quad(R)-2-((R)-1-h y d r o x y-12-((1 S, 2 R)-2-(14-((1 S, 2 R)-2-$ eicosylcyclopropyl)tetradecyl)cyclopropyl)dodecyl)hexacosanoate (16e)}

(a) Cesium hydrogen carbonate $(0.0605 \mathrm{~g}, 0.312 \mathrm{mmol})$, tosylate (14) (0.0293 g, 0.0687 $\mathrm{mmol})$ and acid 11e $(0.0711 \mathrm{~g}, 0.0624 \mathrm{mmol})$ [33] gave a thick colourless oil which was purified by column chromatography (hexane/ethyl acetate, 10:1) to afford compound (15e) $(51 \mathrm{mg}, 58 \%) ;[\alpha]_{D}^{23}+3.6\left(c 0.88, \mathrm{CHCl}_{3}\right) ; \delta_{\mathrm{H}}\left(400 \mathrm{MHz}, \mathrm{CDCl}_{3}\right): 7.37-7.26(10 \mathrm{H}, \mathrm{m}), 4.68$ $(1 \mathrm{H}, \mathrm{d}, J 11.8 \mathrm{~Hz}), 4.65(1 \mathrm{H}, \mathrm{d}, J 11.9 \mathrm{~Hz}), 4.55$ (2H, br.s), $4.43(1 \mathrm{H}, \mathrm{dd}, J 4.0,11.7 \mathrm{~Hz}), 4.22$ $(1 \mathrm{H}, \mathrm{dd}, J 5.5,11.7 \mathrm{~Hz}), 3.86-3.80(1 \mathrm{H}, \mathrm{m}), 3.67-3.56(3 \mathrm{H}$, including br dd $J 1.6,5.4 \mathrm{~Hz}$ at 3.60), $2.45(1 \mathrm{H}, \mathrm{d}, J 7.9 \mathrm{~Hz}), 2.43(1 \mathrm{H}, \mathrm{br} . \mathrm{dd}, J 3.5,7.4 \mathrm{~Hz}) 1.85-0.97(134 \mathrm{H}, \mathrm{m}), 0.89$ $(6 \mathrm{H}, \mathrm{t}, J 7.2 \mathrm{~Hz}), 0.70-0.61(4 \mathrm{H}, \mathrm{m}), 0.60-0.57(2 \mathrm{H}, \mathrm{dt}, J 4.0,8.5 \mathrm{~Hz}),-0.32(2 \mathrm{H}$, br q, $J$ $5.2 \mathrm{~Hz}) ; \delta_{\mathrm{C}}\left(101 \mathrm{MHz}, \mathrm{CDCl}_{3}\right): 175.4,138.0,137.8,128.4,128.3,127.7,127.6,127.5,121.9$, $75.7,73.4,72.3,72.0,69.5,63.4,51.3,35.5,31.9,30.1,29.7,29.6,29.5,29.45,29.4,29.3$, 28.6, 27.4, 25.7, 22.6, 15.7, 14.0, 10.8; $v_{\max }: 3435,2917,2850,1732,1468 \mathrm{~cm}^{-1}$.

(b) Palladium hydroxide on activated charcoal $(0.0063 \mathrm{~g})$ and ester (15e) $(0.0425 \mathrm{~g}, 0.0305$ mmol) gave a thick oil; column chromatography (chloroform/methanol, 20:1) gave the title compound (16e) $(27 \mathrm{mg}, 74 \%)$ [MALDI-Found $(\mathrm{M}+\mathrm{Na})^{+}:$1234.2001, $\mathrm{C}_{81} \mathrm{H}_{158} \mathrm{NaO}_{5}$, requires: 1234.2007$] ;[\alpha]_{D}^{23}+2.3\left(c\right.$ 5.2, $\left.\mathrm{CHCl}_{3}\right) ; \delta_{\mathrm{H}}\left(400 \mathrm{MHz}, \mathrm{CDCl}_{3}+\right.$ few drops of $\left.\mathrm{CD}_{3} \mathrm{OD}\right): 4.22(1 \mathrm{H}, \mathrm{dd}, J 4.4,11.5 \mathrm{~Hz}), 4.12(1 \mathrm{H}, \mathrm{dd}, J 6.4,11.5 \mathrm{~Hz}), 3.89-3.83(1 \mathrm{H}, \mathrm{m})$, $3.67-3.58(2 \mathrm{H}$, including br dd, $J 4.0,11.1 \mathrm{~Hz}$ at 3.61$), 3.55(1 \mathrm{H}, \mathrm{dd}, J 5.8,11.6 \mathrm{~Hz}),(1 \mathrm{H}$, ddd, $J 4.4,7.9,10.0 \mathrm{~Hz}), 1.79-0.96(137 \mathrm{H}, \mathrm{m}), 0.85(6 \mathrm{H}, \mathrm{t}, J 6.8 \mathrm{~Hz}), 0.66-0.57(4 \mathrm{H}, \mathrm{m})$, $0.53(2 \mathrm{H}, \mathrm{dt}, J 4.4,8.4 \mathrm{~Hz}),-0.36(2 \mathrm{H}$, br.q, $J 5.1 \mathrm{~Hz}) ; \delta_{\mathrm{C}}\left(126 \mathrm{MHz}, \mathrm{CDCl}_{3}+\right.$ few drops of $\left.\mathrm{CD}_{3} \mathrm{OD}\right): 175.4,72.4,69.6,65.0,62.8,52.4,31.7,30.0,29.4,29.1,29.0,28.5,27.2,25.1$, $22.4,15.5,13.8,10.6 ; v_{\max }: 3400,3017,2917,2850,1733,1468 \mathrm{~cm}^{-1}$.

\section{$4.11 \quad(S)-2,3-d i h y d r o x y p r o p y l \quad(R)-2-((R)-1-h y d r o x y-18-((1 R, 2 S)-2-((17 S, 18 S)-17-$ methoxy-18-methylhexatriacontyl)cyclopropyl)octadecyl)hexacosanoate (16f)}

(a) Cesium hydrogen carbonate $(0.0351 \mathrm{~g}, 0.181 \mathrm{mmol})$, tosylate (14) (0.0170 g, 0.0399 $\mathrm{mmol})$ and acid $11 \mathrm{f}(0.0455 \mathrm{~g}, 0.0362 \mathrm{mmol})$ [38]. A thick colourless oil residue which was purified by column chromatography (hexane/ethyl acetate, 10:1) to afford compound (15f) (40 mg, 72\%); $[\alpha]_{D}^{23}+6.4\left(c 0.50, \mathrm{CHCl}_{3}\right) ; \delta_{\mathrm{H}}\left(400 \mathrm{MHz}, \mathrm{CDCl}_{3}\right): 7.39-7.26(10 \mathrm{H}, \mathrm{m}), 4.70$ $(1 \mathrm{H}, \mathrm{d}, J 11.8 \mathrm{~Hz}), 4.66(1 \mathrm{H}, \mathrm{d}, J 11.8 \mathrm{~Hz}), 4.57$ (2H, br.s), 4.44 (1H, dd, J 4.1, $11.6 \mathrm{~Hz}), 4.23$ $(1 \mathrm{H}, \mathrm{dd}, J 5.5,11.7 \mathrm{~Hz}), 3.85(1 \mathrm{H}, \mathrm{m}), 3.69-3.57(3 \mathrm{H}$, including br dd, $J 1.6,5.4 \mathrm{~Hz}$ at 
3.62), 3.37 (3H, s), 2.98 (1H, br.p, J $3.8 \mathrm{~Hz}), 2.47$ (1H, d, J $7.9 \mathrm{~Hz}), 2.44$ (1H, br.dd, J 4.5, $8.5 \mathrm{~Hz}), 1.88-1.03(147 \mathrm{H}, \mathrm{m}), 0.91(6 \mathrm{H}, \mathrm{t}, J 7.1 \mathrm{~Hz}), 0.89(3 \mathrm{H}, \mathrm{d}, J 6.8 \mathrm{~Hz}), 0.71-0.63$ $(2 \mathrm{H}, \mathrm{m}), 0.58(1 \mathrm{H}, \mathrm{dt}, J 4.0,8.3 \mathrm{~Hz}),-0.31(1 \mathrm{H}$, br.q, $J 5.2 \mathrm{~Hz}) ; \delta_{\mathrm{C}}\left(101 \mathrm{MHz}, \mathrm{CDCl}_{3}\right): 175.4$, 128.4, 128.3, 127.7, 127.6, 127.5, 85.3, 75.7, 73.4, 72.2, 72.0, 69.5, 68.0, 63.4, 57.6, 51.3, 38.6, 35.4, 35.2, 32.3, 31.8, 30.4, 30.3, 30.1, 29.9, 29.8, 29.7, 29.6, 29.5, 29.4, 29.3, 28.8, 28.6, 27.5, 27.4, 26.0, 22.6, 15.7, 14.8, 14.0, 10.8; $v_{\max }$ : 3030, 2923, 2853, 1733, $1496 \mathrm{~cm}^{-1}$.

(b) Palladium hydroxide on activated charcoal $(0.0032 \mathrm{~g})$ and ester $(\mathbf{1 5 f})(0.0215 \mathrm{~g}, 0.0142$ mmol) gave a thick colourless oil; column chromatography (chloroform/methanol, 20:1) gave the title compound (16f) (18 mg, 92\%) [MALDI-Found (M+Na) ${ }^{+}: 1350.3203, \mathrm{C}_{88} \mathrm{H}_{154} \mathrm{NaO}_{6}$, requires: 1350.3208$] ;[\alpha]_{D}^{23}+1.9\left(c 0.74, \mathrm{CHCl}_{3}\right) ; \delta_{\mathrm{H}}\left(400 \mathrm{MHz}, \mathrm{CDCl}_{3}+\right.$ few drops of $\left.\mathrm{CD}_{3} \mathrm{OD}\right): 4.22(1 \mathrm{H}, \mathrm{dd}, J 4.2,11.5 \mathrm{~Hz}), 4.12(1 \mathrm{H}, \mathrm{dd}, J 6.4,11.5 \mathrm{~Hz}), 3.89-3.83(1 \mathrm{H}, \mathrm{m})$, $3.71-3.58(2 \mathrm{H}$, including br.dd, $J 4.1,11.5 \mathrm{~Hz}$ at $\delta 3.61), 3.55(1 \mathrm{H}$, dd, $J 5.8,11.5 \mathrm{~Hz}), 3.31$ (3H, s), 2.94 (1H, br.p, J 3.7 Hz), 2.40 (1H, ddd, J 4.8, 7.4, $10.4 \mathrm{~Hz}), 1.68-0.94(150 \mathrm{H}, \mathrm{m})$, $0.85(6 \mathrm{H}, \mathrm{t}, J 6.9 \mathrm{~Hz}), 0.82(3 \mathrm{H}, \mathrm{d}, J 6.9 \mathrm{~Hz}), 0.65-0.58(2 \mathrm{H}, \mathrm{m}), 0.52(1 \mathrm{H}, \mathrm{dt}, J 4.0,8.1$ $\mathrm{Hz}),-0.37(1 \mathrm{H}$, br.q, $J 5.2 \mathrm{~Hz}) ; \delta_{\mathrm{C}}\left(101 \mathrm{MHz}, \mathrm{CDCl}_{3}+\right.$ few drops of $\left.\mathrm{CD}_{3} \mathrm{OD}\right): 175.5,85.5$, 72.6, 69.7, 65.1, 63.0, 58.0, 52.5, 35.2, 35.0, 33.0, 31.8, 30.4, 30.1, 29.8, 29.7, 29.6, 29.55, $29.5,29.4,29.3,29.2,29.1,28.6,27.4,27.3,26.0,25.3,22.6,15.7,14.7,14.0,10.8 ; v_{\max }$ : $3389,3017,2919,2850,1733,1467 \mathrm{~cm}^{-1}$.

\subsection{2 (S)-2,3-dihydroxypropyl(2R)-2-((1R)-1-hydroxy-16-((1R,2S)-2-(20-methyl-19-oxo- octatriacontyl)cyclopropyl)hexadecyl)hexacosanoate (16g)}

(a) Cesium hydrogen carbonate $(0.0572 \mathrm{~g}, 0.295 \mathrm{mmol})$, tosylate (14) (0.0277 g, 0.0649 $\mathrm{mmol})$ and acid $11 \mathrm{~g}(0.0731 \mathrm{~g}, 0.0590 \mathrm{mmol})$ [35] gave a thick colourless oil which was purified by column chromatography (hexane/ethyl acetate, 10:1) to afford compound (15g), $(52 \mathrm{mg}, 59 \%) ;[\alpha]_{D}^{23}+6.5\left(c 0.55, \mathrm{CHCl}_{3}\right) ; \delta_{\mathrm{H}}\left(400 \mathrm{MHz}, \mathrm{CDCl}_{3}\right): 7.31-7.05(10 \mathrm{H}, \mathrm{m}), 4.60$ $(1 \mathrm{H}, \mathrm{d}, J 11.8 \mathrm{~Hz}), 4.57$ (1H, d, J 11.8 Hz), 4.47 (2H, br.s), 4.35 (1H, dd, J 4.0, $11.7 \mathrm{~Hz}), 4.14$ $(1 \mathrm{H}, \mathrm{dd}, J 5.5,11.7 \mathrm{~Hz}), 3.80-3.71(1 \mathrm{H}, \mathrm{m}), 3.58-3.48(3 \mathrm{H}$, including br dd, $J 1.4,5.4 \mathrm{~Hz}$ at 3.52), $2.48-2.38(2 \mathrm{H}$, including $\mathrm{OH}$ proton at 2.43$), 2.38-2.29(3 \mathrm{H}$, including $\mathrm{dt}, J 5.4$, $7.9 \mathrm{~Hz}$, at 2.35), $1.75-1.01(144 \mathrm{H}, \mathrm{m}), 0.98(3 \mathrm{H}, \mathrm{d}, J 6.9 \mathrm{~Hz}), 0.81(6 \mathrm{H}, \mathrm{t}, J 6.7 \mathrm{~Hz}), 0.62-$ $0.53(2 \mathrm{H}, \mathrm{m}), 0.49(1 \mathrm{H}, \mathrm{dt}, J 4.0,8.5 \mathrm{~Hz}),-0.40(1 \mathrm{H}$, br.q, $J 5.1 \mathrm{~Hz}) ; \delta_{\mathrm{C}}\left(101 \mathrm{MHz}, \mathrm{CDCl}_{3}\right)$ : 215.0, 175.7, 138.0, 128.4, 128.3, 127.7, 127.6, 127.5, 75.7, 73.4, 72.2, 72.0, 69.5, 63.4, 51.3, 46.2 , 41.0, 35.4, 33.0, 31.8, 30.1, 29.6, 29.55, 29.5, 29.4, 29.35, 29.3, 29.2, 28.6, 27.4, 27.2, 25.7, 23.7, 23.6, 22.6, 16.3, 15.7, 14.0, 10.8; $v_{\max }$ : 2918, 2850, 1717, $1467 \mathrm{~cm}^{-1}$.

(b) As above, using palladium hydroxide on activated charcoal $(0.0075 \mathrm{~g})$ and ester (15g) $(0.0505 \mathrm{~g})$, eluting with chloroform/methanol (40:1) gave the title compound (16g) (38 $\mathrm{mg}$, $87 \%)$ [MALDI-Found $(\mathrm{M}+\mathrm{Na})^{+}: 1334.2890, \mathrm{C}_{87} \mathrm{H}_{170} \mathrm{NaO}_{6}$, requires: 1334.2895]; $[\alpha]_{D}^{23}+2.8$ (c 3.6, $\left.\mathrm{CHCl}_{3}\right)$, which showed $\delta_{\mathrm{H}}\left(400 \mathrm{MHz}, \mathrm{CDCl}_{3}+\right.$ few drops of $\left.\mathrm{CD}_{3} \mathrm{OD}\right): 4.22(1 \mathrm{H}, \mathrm{dd}, J$ $4.2,11.4 \mathrm{~Hz}), 4.11(1 \mathrm{H}, \mathrm{dd}, J 6.5,11.4 \mathrm{~Hz}), 3.89-3.81(1 \mathrm{H}, \mathrm{m}), 3.68-3.57(2 \mathrm{H}$, including br dd $J 4.3,11.5 \mathrm{~Hz}$ at $\delta 3.61), 3.54(1 \mathrm{H}, \mathrm{dd}, J 5.8,11.6 \mathrm{~Hz}), 2.53-2.44(1 \mathrm{H}, \mathrm{m}), 2.38(3 \mathrm{H}$, including br.t, $J$ 2.38), $1.68-1.05(147 \mathrm{H}, \mathrm{m}), 1.01(3 \mathrm{H}, \mathrm{d}, J 6.9 \mathrm{~Hz}), 0.84(6 \mathrm{H}, \mathrm{t}, J 6.7 \mathrm{~Hz})$, $0.65-0.57(2 \mathrm{H}, \mathrm{m}), 0.52(1 \mathrm{H}, \mathrm{dt}, J 4.1,8.4 \mathrm{~Hz}),-0.37(1 \mathrm{H}$, br q, $J 5.2 \mathrm{~Hz}) ; \delta_{\mathrm{C}}(126 \mathrm{MHz}$, $\mathrm{CDCl}_{3}+$ few drops of $\left.\mathrm{CD}_{3} \mathrm{OD}\right): 216.0,175.5,72.6,69.7,65.1,63.0,52.5,46.3,41.1,35.0$, 
$32.9,31.8,30.1,29.7,29.6,29.55,29.5,29.45,29.4,29.35,29.3,29.25,29.2,29.15,29.1$, 28.6, 27.4, 27.2, 25.3, 23.6, 22.6, 16.2, 15.7, 14.0, 10.8; $v_{\max }: 3396,3017,2922,2853,1713$, $1467 \mathrm{~cm}^{-1}$.

\section{Acknowledgements}

OTA wishes to thank the Iraqi Ministry of Higher Education and Scientific Research and Mosul University for the award of a PhD studentship. We thank the EPSRC UK National Mass Spectrometry Facility at Swansea University and Dr Paul Gates (Bristol University) for carrying out accurate mass measurements.

\section{References}

[1] Verschoor, J.A., Baird, M.S., Grooten, J., 2012. Towards understanding the functional diversity of cell wall mycolic acids of Mycobacterium tuberculosis. Prog. Lipid Res. 51, 325 - 339.

[2] Bloch, H., Defaye, J., Lederer, E.,1956. Bull. Soc.Chim. Biol. 38, 1301.

[3] Bloch, H., Defaye, J., Lederer, E., Noll, H., 1957. Constituents of a toxic-lipid obtained from Mycobacterium tuberculosis. Biochim. Biophys. Acta 23, $312-321$.

[4] Noll, H., 1957. The chemistry of some native constituents of the purified wax of Mycobacterium tuberculosis. J. Biol. Chem. 224, 149 - 164.

[5] Noll, H., Jackim, E., 1958. The chemistry of the native constituents of the acetone-soluble fat of Mycobacterium tuberculosis (Brevannes): i. Glycerides and phosphoglycolipides. J. Biol. Chem. 232, $903-917$.

[6] Tsumita, T, 1956. Studies on the lipid of BCG. Glyceryl mono-mycolate in the wax C fraction of the lipid of BCG. Jpn. J. Med. Sci. Biol. 9, 205 - 216.

[7] Silva, C.L., Ioneda, T., 1977. Purification and characterization of mononocardomycoloylglycerol from Nocardia rhodochrous. Chem. Phys. Lipids 20, 217 - 223.

[8] Ioneda, T., Silva, C.L., 1979. Purification of 1-monoacylglycerols containing alpha-branched-betahydroxylated fatty-acids from lipids of corynebacterium-pseudotuberculosis. Chem. Phys. Lipids 25 , $85-91$.

[9] Silva, C.L., Ioneda, T., 1980. Monomycoloylglycerol of nocardia-asteroides. Chem. Phys. Lipids 27 , $43-48.9$

[10] Ioneda, T., Ono, S.S., 1996. Chromatographic and mass spectrometric analyses of 1-monomycoloyl glycerol fraction from Rhodococcus lentifragmentus as per-O-benzoyl derivatives. Chem. Phys. Lipids $81,11-19$.

[11] Batrakov, S.G., 1985. The specific lipids of mycobacteria and related organisms. Khimiya Prirodnykh Soedinenii 147-172

[12] Layre, E., Collmann, A., Bastian, M., Mariotti, S., Czaplicki, J., Prandi, J., Mori, L., Stenger, S., De Libero, G., Puzo, G., Gilleron, M., 2009. Mycolic Acids Constitute a Scaffold for Mycobacterial Lipid Antigens Stimulating CD1-Restricted T Cells. Chem. Biol. 16, 82 - 92.

[13] Moody, D.B., Briken, V., Cheng, T-Y., Roura-Mir, C., Guy, M. R., Geho, D.H., Tykocinski, M.L., Besra, G.S., Porcelli, S.A., 2002. Lipid length controls antigen entry into endosomal and nonendosomal pathways for CDIb presentation. Nature Immunology 3, 435 - 442.

[14] Hattori, Y., Matsunaga, I., Komori, T., Urakawa, T. Nakamura, T., Fujiwara, N., Hiromatsu, K., Harashim, H., Sugita, M., 2011. Glycerol monomycolate, a latent tuberculosis-associated mycobacterial lipid, induces eosinophilic hypersensitivity responses in guinea pigs. Biochem. Biophys. Res. Commun. 409, 304 - 307.

[15] Hattori, Y., Morita, D., Fujiwara, N., Mori, D., Nakamura, T., Harashima, H., Yamasaki, S., Sugita, M., 2014. Glycerol Monomycolate Is a Novel Ligand for the Human, but Not Mouse Macrophage Inducible C-type Lectin, Mincle. J. Biol. Chem., 289, 15405 - 15412.

[16] Richardson, M.B., Torigoe, S., Yamasaki, S., Williams, S.J., 2015. Mycobacterium tuberculosis $\beta$ gentiobiosyl diacylglycerides signal through the pattern recognition receptor Mincle: total synthesis and structure activity relationships. Chem. Commun. 51, $15027-15030$. 
[17] van der Peet, L., Nagata, M., Shah, S., White, J.M., Yamasaki, S., Williams, S.J., 2016. Lipid structure influences the ability of glucose monocorynomycolate to signal through Mincle P. Org. Biomol. Chem. 14, 9267 - 9277.

[18] Andersen, C.S., Agger, E.M., Rosenkrands, I., Gomes, J. M., Bhowruth, V., Gibson, K.J.C., Petersen, R.V., Minnikin, D.E., Besra, G.S., Andersen, P., 2009. A Simple Mycobacterial Monomycolated Glycerol Lipid Has Potent Immunostimulatory Activity. J. Immunol. 182, 424 - 432.

[19] Bhowruth, V., Minnikin, D.E., Agger, E.M., Andersen, P.B., 2009. Adjuvant properties of a simplified C32 monomycoloylglycerol analogue. Bioorg. Med. Chem. Lett. 19, 2029 - 2032.

[20] Andersen, C.A.S., Rosenkrands, I., Olsen, A.W., Nordly, P., Christensen, D., Lang, R., Kirschning, C., Gomes, J.M., Bhowruth, V., Minnikin, D.E., Besra, G.S., Follmann, F., Andersen, P., Agger, E.M., 2009. Novel Generation Mycobacterial Adjuvant Based on Liposome-Encapsulated Monomycoloyl Glycerol from Mycobacterium bovis Bacillus Calmette-Guerin. J Immunol. 183, 2294 - 2302.

[21] Nordly, P., Korsholm, K.S., Pedersen, E.A., Khilji, T.S., Franzyk, H., Jorgensen, L., Nielsen, H.M., Agger, E.M., Foged, C., 2011. Incorporation of a synthetic mycobacterial monomycoloyl glycerol analogue stabilizes dimethyldioctadecylammonium liposomes and potentiates their adjuvant effect in vivo. Eur. J. Drug Metab. Pharmacokinet. 77, 89 - 98.

[22] Martin-Bertelsen, B., Korsholm, K.S., Rose, F., Nordly, P., Franzyk, H., Andersen, P., Agger, E. M., Christensen, D., Yaghmura, A., Foged, C., 2013. The supramodular structure is decisive for the immunostimulatory properties of synthetic analogues of a mycobacterial lipid in vitro. RSC Adv. 3, $20673-20683$.

[23] Tima, H.G., Huygen, K., Romano, M., 2016. Innate signaling by mycobacterial cell wall components and relevance for development of adjuvants for subunit vaccines. Expert Review of Vaccines, 15, 1409 - 1420.

[24] Martin-Bertelsen, B., Yaghmur, A., Franzyk, H., Justesen, S., Kirkensgaard, J. J. K., Foged, C., 2016. Conserved Molecular Superlattices in a Series of Homologous Synthetic Mycobacterial Cell-Wall Lipids Forming Interdigitated Bilayers. Langmuir, 32, 12693-12701.

[25] Schmidt, S. T., Khadke, S., Korsholm, K. S., Perrie, Y., Rades, T., Andersen, P., Foged, C., Christensen, D., 2016. The administration route is decisive for the ability of the vaccine adjuvant CAF09 to induce antigen-specific $\mathrm{CD}^{+} \mathrm{T}$-cell responses: The immunological consequences of the biodistribution profile. J. Controlled Rel., 239, 107-117.

[26] Karlsen, K., Korsholm, K. S., Mortensen, R., Ghiasi, S. M., Andersen, P., Foged, C., Christensen, D., 2014. A stable nanoparticulate DDA/MMG formulation acts synergistically with CpG ODN 1826 to enhance the CD4(+) T-cell response. Nanomedicine, 9, 2625-2638.

[27] Chen, J.M., German, G.J., Alexander, D.C., Ren, H., Tan, T., Liu, J., 2006. Roles of Lsr2 in Colony Morphology and Biofilm Formation of Mycobacterium smegmatis. J. Bacteriol. 633 - 641.

[28] Tima, H.G., unpublished results.

[29] Tima, H.G., Al Dulayymi, J.R., Denis, O., Lehebel, P., Baols, K.S., Mohammed, M.O., L'Homme, L., Sahb, M.M., Potemberg, G., Legrand, S., Lang, R., Beyaert, R., Piette, J., Baird, M.S., Huygen, K., Romano, M., 2017. Inflammatory Properties and Adjuvant Potential of Synthetic Glycolipids Homologous to Mycolate Esters of the Cell Wall of Mycobacterium tuberculosis. J. Innate Immun. 9, $162-180$.

[30] Chancellor, A., Tocheva, A.S., Cave-Ayland, C., Tezera, L., White, A., Al Dulayymi, J.R., Bridgeman, J.S., Wilson, S., Tebruegge, M., Marshall, B., Sharpe, S., Elliott, T., Skylaris, C.-K., Essex, J.W., Baird, M.S., Gadola, S., Elkington, P., Mansour, S., 2017. CD1b-restricted GEM T cell responses are modulated by Mycobacterium tuberculosis mycolic acid alkyl chains. Submitted for publication.

[31] Al Dulayymi, J.R., Baird, M.S., Maza-Iglesias, M., Hameed, R.T., Baols, K.S., Muzael, M., Saleh, A.D., 2014. Synthetic trehalose di- and mono-esters of $\alpha$-, methoxy- and keto-mycolic acids. Tetrahedron 70, 9836 - 9852.

[32] Katoch, R.,Trivedi, G.K., Phadke, R.S., 1999. 1-[2-Hydroxy-3-octadecan-1'-oate]propyl-2 ",2 ",5 ",5 "tetramethyl pyrolidine-N-oxyl-3 "-carboxylate as a potential spin probe for membrane structure studies. Bioorg. Med. Chem. 7, 2753 - 2758.

[33] Al Dulayymi, J.R., Baird, M.S., Roberts, E., 2005. The synthesis of a single enantiomer of a major alpha-mycolic acid of M. tuberculosis. Tetrahedron 61, 11939 - 11951.

[34] Travis, B.R., Narayan, R.S., Borhan, B., 2002. Osmium Tetroxide-Promoted Catalytic Oxidative Cleavage of Olefins: An Organometallic Ozonolysis. J. Am. Chem. Soc. 124, 3824 - 3825.

[35] Koza, G., Theunissen, C., Al-Dulayymi, J.R., Baird, M.S., 2009. The synthesis of single enantiomers of mycobacterial ketomycolic acids containing cis-cyclopropanes. Tetrahedron 65, $10214-10229$.

[36] Boals, K.S., 2014. Synthesis of mixed cord factors and related compounds. PhD Thesis, Bangor University. 
[37] Miller, G.J., Broberg, K.R., Rudd, C., Helliwell, M.R., Jayson, G.C. and Gardiner, J.M., 2015. A latent reactive handle for functionalising heparin-like and LMWH deca- and dodecasaccharides. Org. Biomol. Chem., 13, 11208 - 11219.

[38] Al Dulayymi, J.R., Baird, M.S., Roberts, E., Deysel, M., Verschoor, J., 2007. The first syntheses of single enantiomers of the major methoxymycolic acid of Mycobacterium tuberculosis. Tetrahedron 63, $2571-2592$. 


\section{Highlights:}

Nine examples of R- and S-glycerol mycolates (GroMMs) based on synthetic mycolic acids matching the overall structures of alpha-, keto- and methoxymycolic acids of Mycobacterium tuberculosis and other mycobacteria. 